\title{
(IM)POSSIBILIDADES ENUNCIATIVAS \\ SOBRE A LÍNGUA INGLESA \\ NO DISCURSO PUBLICITÁRIO \\ DE INSTITUTOS DE IDIOMAS
}

\section{(IM)POSIBILIDADES ENUNCIATIVAS SOBRE EL INGLÉS EN EL DISCURSO PUBLICITARIO DE INSTITUTOS DE LENGUAS EXTRANJERAS}

\author{
ENUNCIATIVE (IM)POSSIBILITIES ABOUT ENGLISH LANGUAGE IN THE DISCOURSE OF \\ PUBLICITY OF FOREIGN LANGUAGE INSTITUTES
}

\author{
Cristiane Carvalho de Paula Brito* \\ Maria de Fátima Fonseca Guilherme* \\ Nathália Gontijo Da Costa*** \\ Universidade Federal de Uberlândia
}

\begin{abstract}
RESUMO: Este trabalho, fundamentado na interface dos estudos da Linguística Aplicada, da Análise do Discurso pecheutiana e de concepções bakhtinianas de linguagem, visa analisar o funcionamento discursivo de enunciados sobre a língua inglesa em websites de institutos de idiomas. Nosso gesto de interpretação em relação ao corpus busca investigar como o discurso capitalista empresarial se imbrica ao discurso do empoderamento e da motivação de forma a apagar e silenciar uma discursividade empresarial por meio da inscrição em uma formação discursiva didático-pedagógica, criando, assim, o efeito de que a preocupação principal dos institutos reside em questões educacionais.
\end{abstract}

PALAVRAS-CHAVE: Linguística Aplicada. Língua Inglesa. Discurso Publicitário.

RESUMEN: Este trabajo, fundamentado en la interfaz de los estudios de la Lingüística Aplicada, del Análisis del Discurso pecheutiana y de concepciones bakhtinianas del lenguaje, tiene como objetivo analizar el funcionamiento discursivo de enunciados sobre la lengua inglesa en websites de institutos de idiomas. Nuestro gesto de interpretación del corpus busca investigar como el discurso capitalista empresarial se relaciona con el discurso del empoderamiento y de la motivación para apagar y silenciar un discurso empresarial por medio de la inscripción en una formación discursiva didáctica-pedagógica, creando, así, el efecto de que la preocupación más importante de los institutos está en las cuestiones educacionales.

PALABRAS-CLAVE: Lingüística Aplicada. Lengua Inglesa. Discurso Publicitario.

\footnotetext{
* Doutora em Linguística Aplicada pela Universidade Estadual de Campinas (UNICAMP). Docente no Instituto de Letras e Linguística da Universidade Federalde Uberlândia (ILEEL/UFU). E-mail: depaulabrito@gmail.com

Doutora em Linguística Aplicada e Estudos da Linguagem pela Pontifícia Universidade Católica de São Paulo (PUCSP). Docente no Instituto de Letras e Linguística da Universidade Federal de Uberlândia (ILEEL/UFU). E-mail: mffguilherme@gmail.com.

*** Graduada em Letras-Inglês e mestre em Estudos Linguísticos na área de Linguística Aplicada pela Universidade Federalde Uberlândia (UFU).E-mail:nathaliagdocs@gmail.com.
} 
ABSTRACT: This work, based on the interface of the studies of Applied Linguistics, of Pecheutian Discourse Analysis and of Bakhtinian concepts of language, aims at analysing the discursive functioning of utterances about the English language in websites of private foreign language institutes. Our gesture of interpretation toward the corpus seeks to investigate how the entrepreneurial capitalist discourse relates to the discourse of empowerment and of motivation that obliterates and silences an entrepreneurial discursivity through its inscription in a didactic-pedagogic discursive formation, thus producing the effect that the institutes are mainly concerned with educational issues.

KEYWORDS: Applied Linguistics. English Language. Discourse of Publicity.

\section{INTRODUÇÃO}

Este trabalho analisa o funcionamento discursivo de enunciados sobre a língua inglesa (LI), veiculados em propagandas de institutos de idiomas que circulam em websites, os quais se configuram em uma eficaz ferramenta publicitária e espaços enunciativos em que os institutos buscam divulgar/vender seus cursos.

A proposta de se (re)pensar a relação língua estrangeira e mídia ancora-se na premissa de que, sendo um "[...] sustentáculo de nossos dias" (MOITA LOPES, 2006, p. 93), um “[...] grande texto da atualidade” (PAYER, 2005), a mídia é capaz de construir/moldar um imaginário social em que representações (tais como as de línguas materna e estrangeira, de falante nativo/não nativo, de aluno e professor etc), são consolidadas e legitimadas ideológica e sócio-historicamente.

Lançar olhares para as discursividades engendradas no contexto da mídia publicitária, cujo propósito maior é a venda de produtos, permite-nos entrever como o Discurso Midiático Institucional (DMI) para o ensino de segundas línguas, conforme nomeado por Guilherme $(2004)^{1}$, significa a relação língua-sujeito-ensino-mercadoria. Ademais, considerando que "[...] a dimensão de fantasia, de encantamento, relação imaginária, estará sempre presente na relação do sujeito com a mercadoria” (NERY, 2005, p. 14), aventamos a possibilidade de afirmar que o DMI assevera o imaginário, há muito naturalizado no Brasil, de que os institutos de idiomas são os espaços considerados legítimos para se aprender línguas estrangeiras (BAGHIN-SPINELLI, 2002; CARMAGNANI, 2009; BRITO; GUILHERME, 2014). Dito de outro modo, a análise do DMI nos parece relevante na medida em que pode incidir na relação que o sujeito estabelece com a LE que ensina e aprende.

Ancoramo-nos na interface da Linguística Aplicada com a Análise do Discurso pecheutiana e em concepções bakhtinianas de linguagem para compreender que inscrições discursivas perpassam as propagandas enunciadas nos websites. Procuramos, pois, identificar os discursos que atravessam esses enunciados, ou seja, a interdiscursividade constitutiva desse discurso midiático publicitário, de forma a problematizar como essa interdiscursividade pode balizar a construção de um imaginário acerca da relação sujeito-língua inglesa, tendo em vista as questões que permeiam os processos de ensino-aprendizagem.

A possibilidade de aventar uma "[...] visão discursiva na/da LA" (CORACINI, 2003, p. 29) advém da compreensão da natureza inter/transdisciplinar dos estudos em Linguística Aplicada, que nos permite "[...] palmilhar novas sendas” (BOHN, 2005, p. 16), investigar a "[...] a complexidade das questões que nos confrontam no cotidiano" (MOITA LOPES, 2006, p. 98). Enfim, partimos de uma Linguística Aplicada que se situa "[...] nas fronteiras tênues e sutis onde diferentes áreas de investigação se encontram" (GUILHERME, 2011, p. 63) e repensa o sujeito em sua constituição linguageira, trazendo à tona sua relação com o sócio-históricocultural e político-ideológico.

Para isso, organizamos o artigo nos seguintes moldes: em um primeiro momento, fazemos referência a alguns estudos que vêm discutindo a relação da língua inglesa na mídia, sob perspectivas discursivas. Em seguida, explicitamos o escopo teóricometodológico que delineia nosso trabalho. Na terceira seção, discutimos nosso gesto de interpretação dos enunciados sobre LI em

${ }^{1}$ Guilherme (2004), em seu estudo, problematiza como os institutos de idiomas, por meio dos discursos de divulgação de seus cursos, podem influenciar o encontro dos sujeitos com a língua outra que aprendem e podem, também, instaurar uma representação para essa inserção dos sujeitos com essa língua. 
websites de institutos de idiomas. Finalmente, alinhavamos alguns fios ao discutir as possíveis incidências desses discursos na relação do aluno brasileiro com a LI.

\section{LÍNGUA INGLESA, DISCURSO E MÍDIA}

Alguns autores apontam como a mídia brasileira, impressa e virtual, sendo "[...] um lugar privilegiado de reafirmação de uma memória nacional relativa ao ensino de línguas" (CARMAGNANI, 2014, p. 349), constrói discursividades sobre o ensino de LEs, especialmente a LI, a qual, por seu status global, está associada a uma economia global, sendo, pois, "[...] vista como uma chave para abrir portas para a mobilidade social dentro e através de fronteiras nacionais” (KUMARAVADIVELU, 2006, p. 135).

Grigoletto (2007), por exemplo, afirma que algumas representações sobre a língua inglesa no discurso da mídia impressa brasileira e sua incidência na construção identitária do sujeito brasileiro têm construído um discurso homogêneo acerca da necessidade de conhecimento de LI para os brasileiros. Para ela, esse discurso provoca efeitos nos sujeitos para que se sintam responsáveis em obter o conhecimento da língua devido às exigências do mercado de trabalho.

O discurso midiático para o ensino-aprendizagem de línguas, segundo Carmagnani (2008), tem atendido a interesses políticoeconômicos, ao funcionar como dispositivo de controle. A partir de uma perspectiva foucaultiana (FOUCAULT, 1990), a autora entende que a mídia utiliza-se de várias ferramentas para apresentar a LE como produto de consumo capaz de levar os aprendizes a obter sucesso pessoal e profissional, pois ela funciona como uma

[...] rede que conecta o(s) discurso(s) sobre ensino-aprendizagem de línguas estrangeiras em várias instituições (educação formal, institutos de línguas, etc.), para vários fins (por exemplo, as exigências do mercado) (CARMAGNANI, 2008, p. 413)

Ao analisar algumas imagens e os enunciados presentes em folders de divulgação de cursos de idiomas, Jurach (2009) afirma que há uma mobilização de discursos a fim de construir um imaginário de que há escolas de idiomas melhores que outras. A mídia opera, pois, imagética e linguisticamente para atrair o futuro aprendiz de LE, dando-lhe a impressão de que sua escolha é livre e independente das discursividades construídas pelo material de divulgação.

Da mesma forma, Damiana (2011, p.885) atenta para uma dominação ideológica das propagandas dos cursos de idiomas. Para a autora, as inscrições discursivas construídas por esses cursos legitimam as relações de poder que existem entre língua e cultura. Há, portanto, "[...] uma representação na materialidade discursiva de um quadro político-econômico-social em que a língua portuguesa e brasileira encontram-se em um plano inferior à língua e cultura inglesa (e/ou norte americanas)”.

Ao analisar os discursos presentes em alguns outdoors de institutos de idiomas, Guilherme (2004) concluiu que o DMI funciona ancorado pela construção de pressupostos neoliberais, naturalizando o processo de ensino-aprendizagem de línguas estrangeiras. Dessa forma, o DMI se apoia no imaginário idealizado de língua, ensino-aprendizagem e, portanto, inatingível, gerando, por exemplo, sentimentos de fracasso e frustração na aprendizagem de uma LE.

Com base em trabalhos como os referidos, pode se argumentar que, ao entrar na rede de sentidos do discurso midiático publicitário, a LI adquire status de mercadoria, tornando-se um produto a ser comprado. Estabelece-se uma relação de uso e troca: 'adquire-se' (mediante a inscrição no curso de inglês ofertado pela propaganda) o saber da LI pela promessa de ascensão profissional ou, por exemplo, de interação com pessoas em qualquer parte do mundo. Se, por um lado, essa relação de consumo já seria esperada na instância publicitária; por outro, não se pode ignorar o fato de que os enunciados que vêm à tona nesse espaço mobilizam memórias acerca do 'saber LI' oriundas de espaços outros (como da pedagogia de ensino de línguas, das teorias de aquisição de linguagem, da psicologia etc), contribuindo para a consolidação de conceitos já amplamente problematizados no âmbito dos processos de formação de professores e de ensino-aprendizagem de línguas. 


\section{LÍNGUA(GEM), MEMÓRIA DISCURSIVA E DIALOGISMO}

Nosso trabalho situa-se teoricamente no campo da Linguística Aplicada (LA) em diálogo com os estudos discursivos de perspectiva pecheutiana e bakhtiniana, diálogo esse que nos permite compreender que o sujeito não é a origem nem a fonte dos sentidos produzidos, uma vez que retoma os "já-ditos", ou seja, é um sujeito que enuncia balizado por uma memória discursiva, aqui compreendida como “[...] um espaço móvel de divisões, de disjunções, de deslocamentos e de retomadas [...]” (PÊCHEUX, 2010, p. 56).

Consideramos, desse modo, que os enunciados presentes nos websites dos institutos de idiomas sobre o saber LI são constitutivos da memória discursiva do sujeito brasileiro e, por essa razão, ao constituir-se nesses discursos, ele os movimenta ou os fixa na sua relação com a língua inglesa. As inscrições discursivas (des)veladas nos enunciados provocam efeitos de sentidos na subjetividade do aprendiz que busca nos websites a língua (idealizada) que quer aprender. O futuro aprendiz é, portanto, interpelado a assumir uma posição subjetiva; ele ocupa um lugar sócio-histórico marcado e se inscreve em determinas formações discursivas que revelam a ideologia que o constitui.

Nas palavras de Grigoletto (2011, p.291),

[...] postular que os sentidos são constituídos no interdiscurso implica o entendimento de que eles povoam a memória discursiva na forma de enunciados cuja origem ficou esquecida (esse é o modo de funcionamento do interdiscurso em um dado discurso) e que vão "oferecendo" fragmentos de identidade para o sujeito do discurso. A mídia é um dos aparelhos que operam nessa inscrição de "matrizes" identificatórias para o sujeito, ao participar da construção do imaginário social.

Nosso estudo, ao problematizar os enunciados nos websites, compreende que a linguagem não possui características de transparência e homogeneidade; pelo contrário, é devido ao seu caráter de opacidade, em relações de tensões e conflitos, que podemos estabelecer uma forma de significação outra, ou seja, podemos construir interpretações e entender como alguns enunciados produzidos estabelecem relações de força e controle.

A linguagem é tomada aqui em sua natureza constitutivamente dialógica, pois está sempre se movendo pela palavra do outro, em um contínuo processo de construção, sendo a interação verbal “[...] a realidade fundamental da língua” (BAKHTIN, 2002 [1929], p. 123). Na esteira do que preconiza Bakhtin (2003 [1953], p. 297), entendemos que cada enunciado

[...] é pleno de ecos e ressonâncias de outros enunciados com os quais está ligado pela identidade da esfera da comunicação discursiva. Cada enunciado deve ser visto antes de tudo como uma resposta aos enunciados precedentes de um determinado campo [...]: ela os rejeita, confirma, completa, baseia-se neles, subtende-os como conhecidos, de certo modo os leva em conta.

Assim, partimos do pressuposto de que há discursos que atravessam os enunciados nas propagandas dos websites dos institutos de idiomas, produzindo efeitos de sentidos, os quais constantemente se (des)estabilizam, tendo em vista as formações ideológicas em que essas instâncias enunciativas se inscrevem.

Isto posto, salientamos que nos inscrevemos em uma LA que se propõe a focalizar a natureza dialógico-polifônica da linguagem, principalmente em relação à produção de sentidos na interação social. Marcada sempre pela enunciação, na movência dos sentidos, a linguagem é "[...] afetada pelos traços culturais do entorno social em que se realiza (BOHN, 2005, p. 19), ou seja, ela constitui os sentidos sócio-histórico-ideologicamente”. Em suma, nos filiamos a uma LA

[...] que busca problematizar questões de uso da linguagem para que se possa melhor compreendê-las, uma LA que propõe intervenções que possam otimizar as relações mediadas pela linguagem e, por conseguinte, uma LA que se compromete com os sujeitos que vivenciam problemas nas diversas situações mediadas pela linguagem. (GUILHERME, 2013, p. 40) 


\section{LI, DISCURSO CAPITALISTA EMPRESARIAL E A (IM)POSSIBILDADE ENUNCIATIVA}

\subsection{PERCURSO TEÓRICO-METODOLÓGICO}

Ao estabelecermos um olhar outro para os enunciados sobre a LI em websites de cursos de idiomas, procuramos compreender como alguns discursos que se materializam na estrutura dos enunciados e das imagens divulgadas por eles funcionam de modo a atrair futuros aprendizes a 'consumir' a LI, o que, como vimos defendendo, pode incidir na relação sujeito-linguagem, ou seja, na relação que esses aprendizes irão construir na alteridade com a língua estrangeira.

Entendemos que as propagandas dos institutos de idiomas se configuram como um gênero em que diferentes materialidades significantes (imagem, fala, som) se imbricam, levando-nos a compreender seu funcionamento não da perspectiva de um acréscimo (como se uma complementasse a outra), mas de entremeio, no qual trabalham a incompletude e a contradição de cada materialidade (LAGAZZI, 2011, p. 402).

Para analisar as manifestações do DMI para o ensino de línguas estrangeiras, buscamos no corpus regularidades enunciativas, isto é, ressonâncias discursivas, as quais se configuram em diferentes modos de enunciar que apontam, interdiscursivamente, para um mesmo sentido. Trata-se, pois, de investigar a "[...] vibração semântica mútua, que tende a construir, no intradiscurso, a realidade de um sentido" (SERRANI, 1998, p. 161).

Cumpre salientar que, na posição de analistas, empreendemos um gesto de interpretação, a partir da compreensão de que

[...] um "mesmo" corpus pode ser descrito/analisado de modos diversos por diferentes linguistas. Ou melhor, nunca estamos diante de um "mesmo" corpus, porque na construção do corpus emerge a subjetividade daquele que o estabelece, juntamente com o modo como a teoria o toca. Isto implica considerar que a estrutura comporta o furo, abrindo espaço para a manifestação de uma subjetividade. (BERTOLDO; AGUSTINI, 2011, p. 123)

Isto significa que é na alteridade pesquisador-objeto de investigação que se dá a construção de um processo analítico em sua singularidade, ou seja, a materialidade linguístico-discursiva aqui analisada traduz nossa posição histórico-ideológica em confronto com uma discursividade publicitária que circula sócio-culturalmente no Brasil desde que os institutos de idiomas foram implementados na década de 70 .

Além disso, tomamos os websites como Instâncias Enunciativas Sujeitudinais (IES), conforme extensão teórica da noção pecheutiana de sujeito, elaborada por Santos (2009), as quais se referem aos lugares social e discursivo que os sujeitos ocupam nos processos enunciativos. A IES diz respeito às inscrições discursivas que se constituem em movência, em constante alteridade, “[...] além de uma memória de sentidos (conhecimentos, eventos, experiências, modelos e representações discursivas) que a perpassa enquanto manifestação-sujeito singularizada do e no processo interpelativo da realização linguageira” (SANTOS, 2009, p. 90).

Dado que o propósito dessas IES é divulgar/vender cursos de línguas estrangeiras, partimos do pressuposto de que o discurso capitalista empresarial sustenta as representações sobre a LI, funcionando dialogicamente com outros discursos. Há, pois, um conglomerado de vozes que são evocadas (e que se confrontam) quando as instâncias enunciam sobre a língua. Desse modo, no funcionamento discursivo, tentam-se apagar os enunciados que seriam próprios de uma posição-sujeito empresário (cujo interesse primário seria obter lucro pela venda de uma mercadoria, no caso a LI), por meio da inscrição em uma formação discursiva pedagógica, criando, assim, o efeito de que a preocupação principal das instituições recai em questões educacionais.

Em nosso gesto de interpretação, elencamos dois discursos principais, os quais parecem nortear, interdiscursivamente, o funcionamento dos enunciados de forma a apagar o discurso capitalista empresarial, a saber: o discurso do empoderamento e o discurso da motivação. É importante frisar que esses discursos se interconstituem, funcionam de forma imbricada e aqui os separamos por razões didático-analíticas. 


\subsection{LÍNGUA INGLESA E A (IM)POSSIBILIDADE DO EMPODERAMENTO}

O discurso do empoderamento funciona produzindo sentidos de que a LI ensinada pela referida IES é uma língua que confere ao aprendiz um status inquestionável de possibilidade de interação com outros falantes. Vejamos:

(01) Real life, real English - Welcome to the $X^{2}$ Experience.

(02) O inglês é aqui, é agora, é para já. Quem aprende inglês quer mais do que ler ou falar. Quer interagir com o mundo, participar dos acontecimentos e escrever a própria história numa língua - mais do que nunca - universal.

(03) Você se sente um peixe fora d'água quando a conversa é em inglês?

(04) Cursos de inglês - com os cursos de inglês do X, nada abala sua confiança.

Os enunciados 01 e 02, ambos da mesma instituição, são acompanhados pela imagem de uma garota adolescente, branca e loira, com um grande sorriso no rosto e, em segundo plano, uma rua aparentemente bonita, organizada, limpa, cheia de árvores e com vários carros estacionados. Esse cenário acena para uma interdiscursividade em que vozes de um estereótipo de contexto de ensinoaprendizagem de línguas estrangeiras se faz ecoar, ou seja, há um grupo étnico aqui privilegiado que é feliz e que vive confortavelmente em um lugar privilegiado.

No enunciado 01, nota-se o uso destacado do adjetivo real, o qual funciona dialogicamente com o discurso (muito propagado por metodologias de ensino, por exemplo) de que a aprendizagem de uma língua estrangeira não pode ser artificial, sem conexão com as práticas de linguagem que efetivamente ocorrem no mundo fora da sala de aula. Ao oferecer a possibilidade de se vivenciar a realidade, por meio de uma língua também real, a IES, fixando um sentido unívoco para o termo 'real', denega as heterogeneidades constitutivas dos sujeitos e abafa a singularidade envolvida em qualquer processo de aprendizagem de uma língua outra.

Ademais, o adjetivo real, ao se encontrar com a palavra English, tenta impor a leitura de que há um inglês que, não sendo verdadeiro, é inferior. Isso é corroborado pelo fato de que o sintagma nominal real English evoca, para o sujeito brasileiro, um imaginário bastante consolidado acerca da Família Real Britânica e sua cultura. Nesse sentido, há um pressuposto de que o inglês britânico sendo real - seja o verdadeiro (haja vista ser essa a variante supostamente ensinada pelo instituto em questão), possível, portanto, de oferecer aos que a possuem um status (poder) equivalente ao da família real britânica.

Pode-se também afirmar que o enunciado 02 corrobora a pretensa efetividade do real English, ao criar a ideia de movimento contínuo e rapidez com O inglês é aqui, é agora, é para já. Assevera-se o imediatismo, característico das relações sociais atuais, deslocando a relação com a língua para a ordem de uma constante pragmaticidade, marca da lógica neoliberal.

Em Quem aprende inglês quer mais do que ler ou falar, chama-nos a atenção o deslocamento de um sentido muito comum no discurso publicitário de LI, a saber: a ênfase na habilidade da oralidade (GUILHERME, 2004, 2009) como objetivo primordial da aprendizagem de uma LE. A IES se coloca como uma instituição que extrapola uma visão instrumentalista de ensino para atribuir ao aprendiz o lugar de agente, aquele que pode interagir com o mundo, participar dos acontecimentos e escrever a própria história numa língua - mais do que nunca - universal. Tais enunciados ressoam as vozes de pedagogias críticas, as quais postulam, dentre outras coisas, a necessidade de se dar voz aos sujeitos nos processos educacionais, promovendo sua emancipação.

Dessa forma, o enunciado 02 faz vir à baila o discurso do empoderamento, ao postular que o aprendiz, possuindo uma língua universal, capaz de conectar tudo a todos, é, antes de tudo, um cidadão global. O enunciado trabalha com a ideia do particularuniversal, uma vez que representa a LI como uma língua de todos, mas que, ao mesmo tempo, abre espaço, de forma dissonante,

\footnotetext{
${ }^{2}$ Neste trabalho, substituiremos os nomes dos institutos de idiomas pela letra "X", uma vez que nosso interesse não está na identidade das instituições, e sim no lugar que elas ocupam enquanto instâncias produtoras de sentidos sobre uma língua estrangeira.
} 
para que a própria história seja escrita. Nessa dissonância, desliza-se o sentido preponderante de que há uma língua inglesa única, homogênea, transparente e que, em sua imanência, pode ser aprendida/adquirida por todos, em qualquer lugar e da mesma forma.

Cumpre salientar que esse efeito de inserção do falante da LI no mundo se dá pelo silenciamento da natureza tensa e conflitiva das interações na/pela linguagem, como se fosse possível, por exemplo, escrever a própria história de maneira harmoniosa. Atente-se para o rosto feliz da garota branca na imagem, produzindo o efeito de que se trata de uma "[...] língua em que se pode ser feliz" (HASHIGUTI, 2013, p. 50) $)^{3}$.

Não se trata aqui de negar a possibilidade de que a língua inglesa, tendo assumido status de língua internacional, falada mais por não-nativos do que nativos, propriamente ditos (GRADDOL, 1999; RAJAGOPALAN, 2004), possa proporcionar situações de interação entre falantes de diferentes partes do mundo, mas de problematizar: primeiro, o lugar de exclusividade atribuído a essa língua (como se só por ela fosse possível hoje escrever a própria história); segundo, o caráter de neutralidade delegado às interações realizadas pelos sujeitos nessa língua.

No enunciado 03, de uma outra instituição, temos a utilização de uma expressão idiomática muito comum (você se sente um peixe fora d'água quando a conversa é em inglês?) que assevera, tanto linguística quanto imageticamente (vê-se a imagem de um pequeno peixe dourado pulando da água), a sensação de não pertencimento do sujeito que não fala a língua inglesa. Em outras palavras, sem a LI não se tem poder, não se pode participar dos acontecimentos do mundo; o não conhecimento exclui, pois, o sujeito desse lugar que as instituições de idiomas alegam existir. A IES, portanto, ao explorar a inscrição no discurso da exclusão que, via de regra, constitui muitos daqueles que aprendem a LI no Brasil, faz com que essa exclusão seja mitigada, ou seja, tenta-se apagar uma memória discursiva que circula sócio-historicamente no Brasil em que os institutos de idiomas e a aprendizagem de língua inglesa não são para todos.

Finalmente, o enunciado 04, de uma instituição distinta das anteriores, traz a promessa do empoderamento no campo emocional com a afirmação categórica nada abala sua confiança, a qual está acompanhada da imagem de jovens sorridentes ao fundo da tela. A questão da segurança em relação à LI é bastante evocada pelo DMI para fazer referência a situações de emprego. Diríamos que há um verdadeiro discurso do medo que instaura a necessidade de se aprender 'bem' uma LE a fim de evitar constrangimentos principalmente no momento de pleitear uma vaga no mercado de trabalho. Defendemos que se trata da crença em um empoderamento emocional, haja vista a quantidade de estudos destinados à compreensão dos aspectos afetivos que incidem no ensino-aprendizagem de línguas, sobretudo no que diz respeito à questão da ansiedade. O discurso capitalista empresarial funciona, assim, de forma a oferecer 'a' solução para as dificuldades na aprendizagem da língua. Oferece-se, portanto, a aprendizagem de uma língua que não existe, uma língua sem equívocos, sem conflitos, sem tensões, uma língua idealizada pelo sujeito, o que nos permite afirmar que é nesse sentido que o DMI funciona de forma a interpelar o sujeito a procurar o instituto na ilusão de que 'naquele lugar' ele encontrará, finalmente, a língua-mercadoria que tanto procurava.

Nos enunciados analisados, observa-se que a imbricação do discurso capitalista empresarial ao discurso do empoderamento se pauta na representação de LI como instrumento de comunicação, existente fora do falante (porém, disponível a ser apropriada por ele) e que funcionaria independente das condições sócio-histórica-ideológicas em que as enunciações ocorrem e do próprio sujeito, o que contribui para a produção de dicotomias como verdadeiro/falso; universal/local; segurança/insegurança; dentro/fora.

${ }^{3}$ Hashiguti (2013) analisa as imagens (concebidas como materialidades visuais) de corpos e rostos, presentes em livros didáticos de língua inglesa, no intuito de compreender seu funcionamento e problematizar seus efeitos para os processos de aprendizagem e para a relação sujeito-LE. 


\subsection{LÍNGUA INGLESA E A (IM)POSSIBILIDADE DA MOTIVAÇÃO}

Um outro discurso que se sobrepõe ao discurso capitalista empresarial é o discurso da motivação. Ao se inscreverem nesse discurso, as IES dialogam com o discurso pedagógico para o ensino de LEs que, sob diferentes perspectivas, enfatiza a necessidade de se motivar o aluno para aprender ${ }^{4}$. Trata-se de uma tentativa de amenizar mais do que supostas dificuldades, o aspecto conflitivo inerente ao processo de ensino-aprendizagem de uma língua outra, o qual, por sua vez, extrapola em muito uma questão meramente metodológica e advém do encontro-confronto com uma outra materialidade significante.
(05) Aprenda inglês em apenas 12 meses e transforme a sua vida. interessa.
(07) X, o jeito mais rápido e fácil de aprender inglês.
(08) Fale inglês como aprendeu português.
(09) O X envolve o aluno no novo idioma.
(10) No X, cada passo com seu inglês é uma comemoração.
(11) Você gosta. Você aprende. X Inglês Definitivo.

(06) Falta pouco. Falta o inglês rápido da X. O único curso de inglês pensado pra ter 18 meses. Criado para ensinar o que

Os enunciados 05, 06 e 07 provocam regularidades enunciativas de que cursos de LEs são muito longos sobretudo pelo interesse das instituições em manterem o aluno para obterem mais lucro. A ideia de 'mais em menos tempo', característica do discurso neoliberal, consolida a imagem de uma língua, como se o processo de aprendizagem pudesse ser controlado, mensurado, enfim, datado.

Dessa forma, tais enunciados asseveram o fenômeno de imediatismo e de consumismo (BAUMAN, 1998), ao propagarem que, em um curto período de tempo (12 meses, 18 meses, rápido), o aprendiz poderá aprender/consumir a LI, com a promessa, inclusive de transformar sua vida. Note-se que a ideia de transformação é reiterada no enunciado criado para ensinar o que interessa, que supostamente rejeita a posição do sujeito capitalista empresarial ao trazer à tona o sentido de que, estando interessadas em lucros, as escolas de idiomas oferecem cursos com conteúdos desnecessários e que se tornam longos para justamente manter o aluno.

Os sentidos de vitória, sucesso, superação e alegria são corroborados pelas imagens de personalidades famosas (um técnico da seleção nacional de vôlei e um renomado cantor gospel, no enunciado 5), que interdiscursivamente produzem o efeito de que, ao estudar LI na referida instituição, o aprendiz alcançará o sucesso e a alegria estampados pelos famosos. É, portanto, nessa discursividade que o sujeito se inscreverá e será levado a procurar o instituto de idiomas, mais uma vez, na ilusão de que, finalmente, a aprendizagem da LE (idealizada) lá se encontra.

O enunciado 06, por sua vez, é acompanhado pela imagem de um homem vestido formalmente, cujo rosto não se pode ver, mas que mostra, no primeiro plano da figura, seu cartão de visitas em que se lê Gabriel Bittencourt. Quase coordenador. Esses enunciados, funcionando dialogicamente com as expressões falta pouco, falta o inglês rápido da X, produzem efeitos de motivação, construindo sentidos de que o curso foi criado especificamente para quem está próximo de alcançar a linha de chegada, no caso o sucesso profissional via língua inglesa, que seria garantido pela IES.

Os enunciados 07 e 08, ambos acompanhados de imagens de pessoas jovens sorrindo, chamam-nos atenção por apresentarem o atrativo da facilidade na aprendizagem da língua. O enunciado $07 \mathrm{o}$ faz explicitamente ao utilizar o adjetivo fácil; todavia, o enunciado 08 tenta instaurar a motivação no aprendiz ao espelhar a aprendizagem da LE à da língua materna (LM), pautando-se na crença de que a entrada em uma língua outra pode ser tão 'natural' quanto a que ocorre na língua primeira, ou seja, como se LM e LE fossem da mesma ordem.

${ }^{4}$ Ver, por exemplo, os trabalhos de Gardner; Lambert (1972); Dörnyei; Ottó (1998); Gómes (1999); Paiva (2011); Ribas (2009); e Ribas e Perine (2014). 
Caracterizar a linguagem dessa maneira significa não levar em conta as perturbações, os questionamentos e as modificações que a língua estrangeira provoca no sujeito uma vez que se aceite que o "[...] eu da língua estrangeira não é, jamais, completamente o da língua materna" (REVUZ, 1998, p. 225) e que "[...] a língua estrangeira vem questionar a relação que está instaurada entre o sujeito e a língua. Essa relação é complexa e estruturante da relação que o sujeito mantém com ele mesmo, com os outros, com o saber” (p. 220).

Os enunciados 09, 10 e 11 ressaltam a suposta preocupação da instituição com o aspecto afetivo do processo de ensinoaprendizagem da LI. Desse modo, para se sobrepor ao discurso capitalista empresarial, a IES se humaniza, projetando-se como uma empresa que motiva o aprendiz, uma vez que se interessa por seu bem-estar (envolve o aluno no novo idioma; você gosta), bem como pelo investimento que ele faz na escola e seu desenvolvimento no idioma (cada passo com seu inglês é uma comemoração; inglês definitivo).

\section{CONSIDERAÇÕES FINAIS}

As análises que aqui empreendemos apontam que as IES, por meio de suas propagandas, se inscrevem no discurso do empoderamento e no discurso da motivação, com vistas a apagar e silenciar o discurso capitalista empresarial e fazer crer que a aprendizagem de uma língua outra é da ordem de uma apropriação/aquisição, semelhante a um produto que se consome e que traz benefícios diversos.

Nosso interesse em compreender o movimento dos sentidos colocado em funcionamento em propagandas de institutos de idiomas tem a ver com o fato de que essas instâncias constroem discursividades que incidem na relação do sujeito brasileiro com a LI, produzindo efeitos de que a escola regular (pública e particular), por exemplo, não é um lugar legítimo para a aprendizagem de uma LE e de que apenas os institutos estariam capacitados para isso; ou de que o processo de ensino-aprendizagem ocorra de forma garantida e harmoniosa (bastando se matricular em determinado instituto).

Cumpre dizer que vários estudos na Linguística Aplicada que trabalham com a noção de empoderamento têm nas reflexões de Paulo Freire sua referência ${ }^{5}$. Para o educador, o empoderamento não consiste em dar poder ao outro, tampouco se limita a um ato individual ou psicológico; na visão freiriana, o empoderamento é concebido como processo de conscientização, essencialmente relacionado aos aspectos sociais e políticos. Trata-se, pois, de

[...] um processo que emerge das interações sociais em que nós, seres humanos, somos construídos e, à medida que, criticamente, problematizamos a realidade, vamos nos "conscientizando", descobrindo brechas e ideologias; tal conscientização nos dá "poder" para transformar as relações sociais de dominação, poder esse que leva à liberdade e à libertação (GUARESCHI, 2008, p. 166).

Contudo, o discurso de empoderamento sustentado pelas IES produz o efeito justamente contrário ao defendido pela visão freiriana, uma vez que se respalda na crença de que é possível 'obter' a língua, e consequentemente, o poder, este sendo, então, visto, como entidade abstrata, neutra, existente independentemente das relações sócio-político-ideológicas nas quais se encontram os sujeitos. Ao postularem tal concepção, as IES corroboram o imaginário de uma língua estática, que funciona em sua imanência, uma língua isenta de historicidade e temporalidade, e, por isso, despolitizada.

Quanto às incidências dos efeitos de sentido do discurso da motivação, podemos apontar os possíveis fracassos na aprendizagem oriundos da frustração dos aprendizes quando, seduzidos pelas promessas de rapidez e eficiência dos cursos oferecidos pelos institutos, deparam-se com o complexo, tenso e conflituoso processo de inscrição em uma língua outra.

\footnotetext{
${ }^{5}$ Ver, por exemplo, Silva e Diniz (2014) e Silva (2015).
} 
Por fim, resta salientar que tais discursos obliteram o fato de que, sendo o aprendiz de uma língua estrangeira um sujeito de língua materna, é preciso frisar que o encontro com uma outra língua é sempre um encontro-confronto de vozes, de subjetividades, de distintas posições históricas, ideológicas, sociais e culturais, o que, por sua vez, faz com que a relação sujeito-língua estrangeira seja sempre singular e heterogênea. Nesse sentido, não há como saber se, ao aprender a língua inglesa, o aprendiz será envolvido pelo idioma, falará com segurança, escreverá a própria história (independentemente do que se entenda por isso), conseguirá um bom emprego etc, já que, sendo a língua(gem) opaca, heterogênea, marcada pela incompletude, também o (seu) saber (ou seu domínio) é da ordem da (im)possibilidade.

Uma visão discursiva de LA pode contribuir para a compreensão dos processos de ensino-aprendizagem e de formação de professores de línguas estrangeiras como "[...] espaços discursivos em que uma multiplicidade de vozes são evocadas de diferentes espaços sociais e de diferentes discursos" (GUILHERME, 2011, p. 75), problematizando discursividades naturalizadas que se tornam historicamente inquestionáveis.

\section{REFERÊNCIAS}

BAGHIN-SPINELLI, D. C. Ser professor (brasileiro) de língua inglesa: um estudo dos processos identitários nas práticas de ensino. 2002. 210f. Tese (Doutorado) - Programa de Pós-Graduação em Linguística Aplicada. Universidade Estadual de Campinas, Campinas, SP, 2002.

BAKHTIN, M. M. (Volochinov). Marxismo e filosofia da linguagem: problemas fundamentais do Método Sociológico na Ciência da Linguagem. Trad. Michel Lahud e Yara Frateschi Vieira. 9. ed. São Paulo: Hucitec, 2002. [1929].

BAKHTIN, M. M. Estética da criação verbal. Introdução e Tradução do russo Paulo Bezerra. 6. ed. São Paulo: Editora WMF Martins Fontes, 2003.[1953]

BAUMAN, Z. Globalização: as consequências humanas. Rio de Janeiro: Jorge Zahar, 1998.

BERTOLDO, E. S.; AGUSTINI, C. L. H. A constituição de corpora em linguística da enunciação. In: SILVEIRA, E. M. (Org.). As bordas da linguagem. Uberlândia: EDUFU, 2011.p. 121-133.

BOHN, H. I. As exigências da pós-modernidade sobre a pesquisa em linguística aplicada no Brasil. In: FREIRE, M. M.; ABRAHÃO, M. H. V. \& BARCELOS, A. M. F. (Org.). Linguística aplicada \& contemporaneidade. Campinas: Pontes Editores, 2005. p. 11-23.

BRITO, C. C. P.; GUILHERME, M. F. F. Memorial de aprendizagem e a formação do professor: vozes constitutivas da relação aprender/ensinar línguas estrangeiras. Revista Brasileira de Linguística Aplicada, Belo Horizonte, v.14, n. 3, p. 511-532, jul./set. 2014.

CARMAGNANI, A. M. G. O discurso da mídia sobre línguas estrangeiras e o desejo do lugar do outro. In: MAGALHÃES, J. S.; TRAVAGLIA, L. C. (Org.). Múltiplas Perspectivas em Linguística. Uberlândia: EDUFU, 2008. p. 413-421.

CARMAGNANI, A. M. G. Linguagem e exclusão: o discurso da mídia sobre o professor e a escola. Revista Brasileira de Linguística Aplicada, Belo Horizonte v. 9, n. 2, p. 499-514, 2009.

CORACINI, M. J. R. F. A Análise do Discurso na Linguística Aplicada. In: CASTRO, S. T. S. (Org.). Pesquisas em lingüistica aplicada: novas contribuições. Taubaté: Cabral Universitária, 2003. p. 17-33.

CARMAGNANI, A. M. G. A Babel controlada: mídia e representação de língua(s) estrangeira(s). In: CORACINI, M. J.; CARMagnani, A. M. G. (Org.). Mídia, exclusão e ensino: dilemas e desafios na contemporaneidade. Campinas, SP: Pontes Editores, 2014. p. 341-357. 
DAMIANA, B. Poder e Supremacia: a venda do ensino de língua inglesa como língua estrangeira no Brasil. In: CONGRESSO NACIONAL DE LINGUÍSTICA E FILOLOGIA, 15., 2011, Rio de Janeiro. Anais... Rio de Janeiro: CiFEFiL, 2011. p. 877-886.

DÖRNYEI, Z.; OTTÓ, I. Motivation in action: a process model of L2 motivation. Working Papers in Applied Linguistics. Thames Valley University, London, v. 4, p. 43-69. 1998.

FOUCAULT, M. Sobre a história da sexualidade. In: FOUCAULT, M. Microfísica do poder. 9. ed. Rio de Janeiro: Graal, 1990. p. 137-162. [1979].

GARDNER, R. C.; LAMBERT, W. E. Attitudes and motivation in second language learning. Rowley, Massachusetts: Newbury House Publishers, 1972.

GÓMES, P. C. A motivação no processo de ensino/aprendizagem de idiomas: um enfoque desvinculado dos postulados de Gardner e Lambert. Trabalhos em Linguística Aplicada, Campinas, v. 34, p. 53-77, jul./dez. 1999.

GRADDOL, D. The decline of the native speaker. In: GRADDOL, D.; MEINHOF, U. H. (Ed.). English in a changing world. Oxford: Catchline, AILA, 1999. p. 57-68.

GRIGOLETTO, M. Língua, discurso e identidade: a língua inglesa no discurso da mídia e a construção identitária de brasileiros. Filologia e Linguística Portuguesa, São Paulo, v. 11, p. 213-227. 2007.

GRIGOLETTO, M. A língua inglesa no discurso publicitário no Brasil: a produção de entre-lugares. Letras, Santa Maria, v. 21, n. 42, p. 287-313, jun. 2011.

GUARESCHI, P. Empoderamento. In: STRECK, D. R.; REDIN, E.; ZITKOSKI, J. J. (Org.). Dicionário Paulo Freire. Belo Horizonte: Autêntica, 2008. p. 165-166.

GUILHERME, M. F. F. O Discurso Midiático Institucional para o Ensino de Segundas Línguas. In: FERNANDES, C. A.; SANTOS, J. B. C. dos. (Org.) Análise do discurso: unidade e dispersão. EntreMeios: Uberlândia, 2004. p. 197-209.

GUILHERME, M. F. F. A construção da subjetividade do graduando em Letras em enunciação institucional sobre competência oral em língua inglesa. In: SANTOS, J. B. C. dos. (Org.). Sujeito e subjetividade: discursividades contemporâneas. Uberlândia: EDUFU, 2009. p.135-156.

GUILHERME, M. F. F. Bakhtin e os estudos em Linguística Aplicada. In: STAFUZZA, G. (Org.). Slovo - O círculo de Bakhtin no contexto dos estudos discursivos. Curitiba: Appris, 2011.p. 59-78.

GUILHERME, M. F. F. Ensino de línguas estrangeiras e formação de professores: deslocamentos epistemo-pragmáticos numa perspectiva celaniana. In: SZUNDY, P. T. C.; BÁRBARA, L. (Org.). Maria Antonieta Alba Celani e a Linguística Aplicada: pesquisadores-multiplicadores em (inter)ações. Campinas: Mercado de Letras, 2013. p. 37-56. 
HASHIGUTI, S. T. O corpo nas imagens em livros didáticos de língua inglesa: repetição e regularização de sentidos. In:

(Org.). Linguística aplicada ao ensino de línguas estrangeiras: práticas e questões sobre e para a formação docente. Curitiba: CRV, 2013. p. 35-54.

JURACH, I. A imagem do sujeito aprendiz de língua estrangeira representada nos folders de propaganda de cursos de idiomas. Coleção HiperSaberes, Santa Maria, v. 2, p. 135-148, dez. 2009. Disponível em: <http://w3.ufsm.br/hipersaberes>. Acesso em: 21 abr. 2014.

KUMARAVADIVELU, B. A linguística aplicada na era da globalização. In: MOITA LOPES, L. P. da (Org.). Por uma linguística aplicada INdisciplinar. São Paulo: Parábola Editorial, 2006. p. 129-148.

LAGAZZI, S. O recorte e o entremeio: condições para a materialidade significante: In: RODRIGUES, E. A.; SANTOS, G. L. dos; BRANCO, L. K. C. (Org.). Análise de discurso no Brasil: pensando o impensado sempre. Uma homenagem a Eni Orlandi. Campinas, SP: RG Editores, 2011.p. 401-410.

MOITA LOPES, L. P. da (Org.). Linguística Aplicada e vida contemporânea: problematização dos construtos que têm orientado a pesquisa. In: (Org.). Por uma linguística aplicada INdisciplinar. São Paulo: Parábola Editorial, 2006. p. 85-107.

NERY, V. C. A. Construção do discurso publicitário na sociedade contemporânea. OPSIS - Revista do NIESC, v. 5, p. 7-21, 2005.

PAIVA, V. L. M. Identity, motivation and autonomy in second language acquisition from the perspective of complex adaptive systems. In: MURRAY, G.; GAO, X.; LAMB, T. (Orgs). Identity, motivation and autonomy in language learning. Bristol, Buffalo, Toronto: Multilingual Matters, 2011.p. 57-72.

PAYER, M. O. Linguagem e sociedade contemporânea - sujeito, mídia, mercado. Rua, Campinas, v. 11, n. 1, p. 9-25, 2005.

PÊCHEUX, M. Papel da Memória. In: ACHARD, P. et al. (Org.). Papel da memória. Trad. José Horta Nunes. Campinas: Pontes, 2010. p. 49-57.

RAJAGOPALAN, K. The concept of 'World English' and its implications for ELT. ELT Journal, v. 58, n. 2, p. 111-117, 2004.

REVUZ, C. A língua estrangeira entre o desejo de um outro lugar e o risco do exílio. In: SIGNORINI, I. (Org.). Lingua(gem) e identidade: elementos para uma discussão no campo aplicado. Campinas, SP: Mercado de Letras. 1998. p. 213-230.

RIBAS, F. C. The role of self-concepts in students' motivation in the Brazilian EFL context. Linguagem \& Ensino, Pelotas, v. 12, p. 463-486, jul./dez. 2009.

RIBAS, F. C.; PERINE, C. M. O que motiva graduandos a iniciar um curso de inglês a distância? Signum: Estudos da Linguagem, Londrina, v. 17, p. 245-271, jun. 2014. 
SANTOS, J. B. C. dos. A instância enunciativa sujeitudinal. In: (Org.). Sujeito e subjetividade: discursividades contemporâneas. Uberlândia: EDUFU, 2009. p. 83-101.

SERRANI, S. M. Abordagem transdisiplinar da enunciação em segunda língua: a proposta Areda. In: CAVALCANTI, M. C.; SIGNORINI, I. (Org.). Linguística aplicada e transdisciplinariedade: questões e perspectivas. Campinas: Mercado de Letras, 1998. p. 143-167.

SILVA, W. R.; DINIZ, A. L. S. Estágio supervisionado obrigatório das licenciaturas como contexto de pesquisa da Linguística Aplicada. Trabalhos em Linguística Aplicada, Campinas, v. 53, n. 2, p. 333-355, jul./dez. 2014.

SILVA, W. R. Gêneros em práticas escolares de linguagem: currículo e formação do professor. Revista Brasileira de Linguística Aplicada, Belo Horizonte, v. 15, n. 4, p. 1023-1055, out./dez. 2015. 